\title{
Impact of macrophage toll-like receptor 4 deficiency on macrophage infiltration into adipose tissue and the artery wall in mice
}

\author{
K. R. Coenen • M. L. Gruen • R. S. Lee-Young • \\ M. J. Puglisi • D. H. Wasserman • A. H. Hasty
}

Received: 9 September 2008 / Accepted: 21 October 2008 / Published online: 4 December 2008

(C) Springer-Verlag 2008

\begin{abstract}
Aims/hypothesis Toll-like receptor 4 (TLR4) is a receptor for saturated fatty acids (SFAs), global deficiency of which has been shown to protect against inflammation, insulin resistance and atherosclerotic lesion formation. Because macrophages express Tlr4 and are important in insulin resistance and atherosclerotic lesion formation due to their infiltration of white adipose tissue (WAT) and the artery wall, respectively, we hypothesised that deficiency of macrophage TLR4 could protect against these disorders.

Methods Bone marrow transplantation of agouti, LDL-

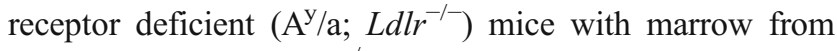
either C57BL/6 or $\operatorname{Tlr} 4^{-1}$ mice was performed. Recipient mice with $\mathrm{Tlr}^{+/+}$marrow (MOTLR4 ${ }^{+/+}$) or with $\mathrm{Tlr}_{4}{ }^{-/}$ marrow (MOTLR $4^{-1}$ ) were then placed on one of four diets: (1) low fat; (2) high fat; (3) high fat rich in SFAs $\left(\mathrm{HF}^{\mathrm{SFA}}\right)$; and (4) $\mathrm{HF}^{\mathrm{SFA}}$ supplemented with fish oil.

Results There were no differences in body composition or plasma lipids between M $\theta \mathrm{TLR} 4^{+/+}$and M $\operatorname{TLR} 4^{-/-}$mice on any of the diets. However, we observed a decrease in some macrophage and inflammatory markers in WAT of female low fat-fed M $\theta \mathrm{TLR} 4^{-/-}$mice compared with MOTLR4 ${ }^{+/+}$ mice. M $\operatorname{TLR} 4^{-/}$mice fed low-fat diet also displayed
\end{abstract}

Electronic supplementary material The online version of this article (doi:10.1007/s00125-008-1221-7) contains supplementary material, which is available to authorised users.

K. R. Coenen • M. L. Gruen · R. S. Lee-Young • M. J. Puglisi

D. H. Wasserman $\cdot$ A. H. Hasty $(\square)$

Vanderbilt University Medical Centre,

Room 702 Light Hall,

Nashville, TN 37232-0615, USA

e-mail: alyssa.hasty@vanderbilt.edu decreased atherosclerotic lesion area. There were no differences in macrophage accrual in WAT or atherosclerosis between MOTLR $4^{+/+}$and MOTLR $4^{-/}$mice fed any of the high-fat diets. Finally, no difference was seen in insulin sensitivity between M $\theta \mathrm{TLR} 4^{+/+}$and MOTLR $4^{-/}$mice fed the $\mathrm{HF}^{\mathrm{SFA}}$ diet.

Conclusions/interpretation These data suggest that under certain dietary conditions, macrophage expression of Tlr4 can be an important mediator of macrophage accumulation in WAT and the artery wall.

Keywords Adipose tissue - Atherosclerosis - Diet . Fatty acids $\cdot$ Insulin resistance $\cdot$ Macrophage $\cdot$ TLR4

\begin{tabular}{|c|c|}
\hline \multicolumn{2}{|c|}{ Abbreviations } \\
\hline ATM & adipose tissue macrophage \\
\hline BMT & bone marrow transplantation \\
\hline $\mathrm{HF}^{\mathrm{SFA}}$ & high-fat diet with SFA source \\
\hline $\mathrm{HF}^{\mathrm{SFA}+\mathrm{FO}}$ & $\mathrm{HF}^{\mathrm{SFA}}$ with added fish oil \\
\hline LDLR & LDL receptor \\
\hline LPS & lipopolysaccharide \\
\hline M1 & classical macrophage markers \\
\hline M2 & alternative activation macrophage markers \\
\hline MIP-1 $\alpha$ & macrophage inflammatory protein- $1 \alpha$ \\
\hline M $\theta$ TLR $4^{+/+}$ & recipient mice with $T l r 4^{+/+}$marrow \\
\hline $\mathrm{M} \theta \mathrm{TLR} 4^{-/-}$ & recipient mice with $T l r 4^{-1-}$ marrow \\
\hline MUFA & monounsaturated fatty acid \\
\hline NMR & nuclear magnetic resonance \\
\hline PUFA & polyunsaturated fatty acid \\
\hline$R_{\mathrm{g}}$ & glucose metabolism index \\
\hline SFA & saturated fatty acid \\
\hline TLR4 & toll-like receptor 4 \\
\hline WAT & white adipose tissue \\
\hline
\end{tabular}




\section{Introduction}

Obesity remains an issue in today's society, with a recent epidemiological study projecting that $41 \%$ of the US population will be obese by 2015 [1]. Obesity is a critical component of the metabolic syndrome, along with hypertension, dyslipidaemia, impaired glucose tolerance and insulin resistance [2-4]. Obese individuals have a two- to threefold increased risk of death from all causes [5], with the majority of risk due to cardiovascular disease [6]. Because obesity is characterised by adipose tissue expansion, much effort is being placed into researching the contribution of adipose tissue to development of metabolic diseases associated with obesity.

One key cell type that may link obesity with metabolic disorders is the macrophage. Macrophages are cells of the innate immune system that have been implicated in development of diseases such as cancer, atherosclerosis and, most recently, insulin resistance [7-11]. Although it has long been known that macrophages infiltrate the artery wall and are integral to the formation of atherosclerotic lesions $[12,13]$, it was recently demonstrated that macrophages infiltrate white adipose tissue (WAT) and may contribute to inflammation and insulin resistance in obesity $[8$, 14]. Studies have shown that these adipose tissue macrophages (ATMs) contribute the majority of pro-inflammatory cytokine production in adipose tissue and that the presence of ATMs precedes hyperinsulinaemia [8, 14]. Importantly for our studies, ATMs have been shown to be derived from bone marrow [14].

Because of the close link between obesity, macrophages and inflammation, the activation of macrophages via tolllike receptor 4 (TLR4) has become an important area of research. TLR4 is a pathogen-associated molecular pattern recognition receptor that is activated by lipopolysaccharide (LPS). The lipid A moiety of LPS contains acylated hydroxyl saturated fatty acids (SFAs). Removal of these or their replacement with polyunsaturated fatty acids (PUFAs) results in a loss of LPS-induced inflammation [15]. This attribute of LPS led to the hypothesis that SFAs could be natural ligands for TLR4, a theory that has been confirmed by several different groups who have shown that the activation of TLR4 by SFAs leads to the induction of c-Jun N-terminal kinase (JNK), extracellular signal-regulated kinase 1/2 (ERK1/2) and phosphoinositide-3 kinase pathways, culminating in inflammatory gene expression [16-19]. TLR4 is able to sense and respond to different types of fatty acids, as SFAs result in activation, while PUFAs block the activation of TLR4 [17-22].

The responsiveness of TLR4 to fatty acids makes TLR4 an appealing intermediary between obesity and recruitment of macrophages to WAT and the artery wall. Recently, global TLR4 deletion studies have delivered conflicting results regarding the role of TLR4 in body composition and macrophage infiltration of WAT in mice challenged with high-fat diets. However, all of the studies shared the common finding that $\mathrm{Tlr}^{-1-}$ mice were protected against inflammation and insulin resistance [18, 23-25]. Our current studies expand upon these findings by investigating the effect of macrophage Tlr4 on insulin resistance, the influx of macrophages to WAT, local inflammation and atherosclerosis.

\section{Methods}

Mice All animal care and experimental procedures were performed with approval from the Institutional Animal Care and Usage Committee of Vanderbilt University. Tlr $4^{-/}$ mice on a C57BL/6 background were kindly provided by S. Uematsu and S. Akira (Department of Host Defense, University of Osaka, Japan). The $\mathrm{Tlr}^{-/-}$mice were subsequently crossed with C57BL/6 mice from our colony. The heterozygous offspring were intercrossed to produce the $T l r 4^{-/-}$and $T l r 4^{+/+}$littermates used as bone marrow donors. The recipient, agouti ( $\left.\mathrm{A}^{\mathrm{y}} / \mathrm{a}\right)$, LDL-receptor (LDLR)-

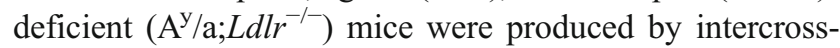
ing $\mathrm{A}^{\mathrm{y}} / \mathrm{a}$ mice with $L d l^{-/-}$mice, both of which were on a C57BL/6 background [26, 27]. These studies were performed in male and female mice; however, data shown are from female mice only.

Bone marrow transplantation For bone marrow transplantation (BMT), bone marrow cells collected from $\mathrm{Tlr}^{-1-}$ and $\mathrm{Tlr}^{+/+}$donors were injected into the retro-orbital venous

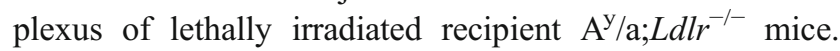
Reconstitution was confirmed by performing PCR for TLR4 genotype of DNA isolated from blood of recipient mice (data not shown).

Diets Mice had free access to food and water throughout the study. They were placed on experimental diets 4 weeks post-BMT and maintained on the respective diets for 12 weeks. All diets (Table 1) were purchased from Research Diets (New Brunswick, NJ, USA). Cocoa butter was selected as the source for high-fat diet with SFA source $\left(\mathrm{HF}^{\mathrm{SFA}}\right)$ to allow for the highest concentration of SFAs in the diet while still providing essential fatty acids.

Total body fat Total body fat was determined by NMR using the Bruker Minispec (Woodlands, TX, USA) in the Mouse Metabolic Phenotyping Centre at Vanderbilt University.

Euglycaemic-hyperinsulinaemic clamps Mice were catheterised at least 5 days before experimentation and euglycaemic-hyperinsulinaemic clamps were performed on conscious mice after a $5 \mathrm{~h}$ fast as previously described [28]. Briefly, a 
Table 1 Composition of experimental diets

\begin{tabular}{|c|c|c|c|c|c|c|c|c|}
\hline \multirow[t]{2}{*}{ Dietary treatment } & \multirow[t]{2}{*}{ Diet name } & \multirow[t]{2}{*}{ Fat source } & \multirow[t]{2}{*}{ Energy from fat $(\%)$} & \multicolumn{3}{|c|}{$\begin{array}{l}\text { Fatty acid composition } \\
\text { (\% of total fat) }\end{array}$} & \multirow[t]{2}{*}{$\begin{array}{l}\text { Cholesterol } \\
\text { (g/kg diet) }\end{array}$} & \multirow[t]{2}{*}{$\begin{array}{l}\text { Sucrose } \\
\text { ( } \mathrm{g} / \mathrm{kg} \text { diet) }\end{array}$} \\
\hline & & & & SFA & MUFA & PUFA & & \\
\hline Low total fat & Low fat & Olive oil & 12 & 14.2 & 72.1 & 13.6 & 1.5 & 341 \\
\hline Low SFA & High fat & Olive oil & 41 & 14.2 & 72.1 & 13.6 & 1.5 & 341 \\
\hline High SFA & $\mathrm{HF}^{\mathrm{SFA}}$ & Cocoa butter & 41 & 62.5 & 34.4 & 3.0 & 1.5 & 341 \\
\hline $\begin{array}{l}\text { High SFA }+n-3 \\
\text { PUFA (fish oil) }\end{array}$ & $\mathrm{HF}^{\mathrm{SFA}+\mathrm{FO}}$ & Cocoa butter + menhaden oil & 41 & 56.0 & 30.4 & 13.6 & 1.5 & 341 \\
\hline
\end{tabular}

Data represent the source, amount and fatty acid composition of fat used in respective diets and were provided by Research Diets, New Brunswick, NJ, USA

$185 \mathrm{kBq}$ bolus of $\left[3{ }^{3} \mathrm{H}\right]$ glucose was given, followed by a constant $1.85 \mathrm{kBq} / \mathrm{min}$ infusion for $90 \mathrm{~min}(t=-90$ to $0 \mathrm{~min})$, which served as the tracer equilibration period. At 0 min the insulin clamp began with a continuous infusion of human insulin at $4 \mathrm{mU} \mathrm{kg}^{-1} \mathrm{~min}^{-1}$ (Humulin R; Eli Lilly, Indianapolis, IN, USA). The $\left[3-^{3} \mathrm{H}\right]$ glucose infusion was increased to $0.27 .4 \mathrm{kBq} / \mathrm{min}$ for the clamp and euglycaemia $(\sim 8.33$ $8.89 \mathrm{mmol} / \mathrm{l}$ ) was maintained by measuring arterial blood glucose every $10 \mathrm{~min}$ and infusing $50 \%$ dextrose as necessary. Following the $120 \mathrm{~min}$ insulin clamp, a $592 \mathrm{kBq}$ bolus of 2-deoxy $\left[{ }^{14} \mathrm{C}\right]$ glucose was given to determine the tissue-specific glucose metabolic index $\left(R_{\mathrm{g}}\right)$ as previously described [28]. At $t=150 \mathrm{~min}$ mice were killed with an overdose of sodium pentobarbital and the soleus, gastrocnemius, superficial vastus lateralis, WAT, liver, heart and brain were excised.

Blood collection and plasma variables After 12 weeks of feeding on their respective diets, mice were fasted overnight before blood was collected. Plasma total cholesterol and triacylglycerol levels were measured using kits (Raichem, San Diego, CA, USA). NEFA measurements were performed using a kit (NEFA-C, Wako, Neuss, Germany). Glucose levels were determined on whole blood using a glucometer (Lifescan OneTouch; Johnson \& Johnson, Northridge, CA, USA). Insulin and leptin measurements were performed by the Vanderbilt Hormone Assay and Analytical Services Core using RIAs.

F4/80 staining of adipose tissue Perigonadal fat pads were extracted upon killing, fixed in 10\% formalin (vol./vol.) and embedded in paraffin. Sections were stained for EGFlike module containing, mucin-like, hormone receptor-like sequence 1 (F4/80) using an antibody from Serotec (Raleigh, NC, USA) at a 1:100 dilution. Secondary antibody (Dako, Glostrup, Denmark) was used at a 1:100 dilution.

Gene expression RNA was isolated from perigonadal WAT using the a kit (RNeasy Mini; Qiagen, Valencia, CA, USA) according to the manufacturer's instructions. Real-time RTPCR was performed using Applied Biosystem 7700 sequence detection system (Foster City, CA, USA) or the iQ5 cycler from BioRad (Hercules, CA, USA). Primer-probe sets were purchased from Applied Biosystem's Assays-on-demand. Gene expression was normalised to $18 \mathrm{~S}$ and the $\Delta \Delta \mathrm{C}_{\mathrm{t}}$ method was used to calculate relative gene expression [29].

Fatty acid composition of adipose tissue Gas chromatography was used to analyse fatty acid composition of the triacylglycerol portion of perigonadal fat pads as described previously [27, 30].

Atherosclerotic lesion area Hearts were excised upon killing, frozen and sectioned at the aortic root. Neutral lipids were stained using Oil-Red-O. Lesion area was quantified using Histometrix version 6 imaging and analysis software (Kinetic Imaging, Durham, NC, USA).

Statistics Statistical analyses were performed using SPSS (SPSS, Chicago, IL, USA) for two-way ANOVA to detect main effects of diet and MOTLR4 genotype on specific phenotypic measures as well as the interactions between these effects. The Bonferroni procedure was used for posthoc analyses. Prism 4 software (GraphPad, La Jolla, CA, USA) was used to perform Student's $t$ test (comparing mice with $T l r 4^{+/+}$versus $T l r 4^{-/-}$bone marrow for each diet). Data are expressed as mean \pm SEM and were considered significant at $p<0.05$.

\section{Results}

Use of BMT to develop a model with macrophage-specific

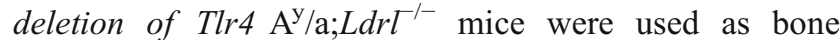
marrow recipients because of their susceptibility to hyperlipidaemia, insulin resistance, obesity and atherosclerosis $[26,27]$. These mice were lethally irradiated followed by transplantation with marrow from $\mathrm{C} 57 \mathrm{BL} / 6$ or $T l r 4^{-/-}$ 
donors (Electronic supplementary material [ESM] Fig. 1) to create recipient mice with $T l r 4^{+/+}$marrow $\left(\mathrm{MOTLR} 4^{+/+}\right.$) and recipient mice with $T l r 4^{-1-}$ marrow $\left(\mathrm{MOTLR} 4^{-/-}\right.$) respectively. At 4 weeks post-BMT, mice were placed on one of four experimental diets (Table 1) for 12 weeks. All diets were high in cholesterol $(0.15 \%)$ and sucrose $(341 \mathrm{~g} / \mathrm{kg}$ diet). The low-fat diet was low in total fat (12\%) and energy $(16.5 \mathrm{~kJ} / \mathrm{g})$ and used olive oil as the fat source, providing $14.2 \%$ of fat from SFAs, $72.1 \%$ from monounsaturated fatty acids (MUFAs) and $13.6 \%$ of fat from PUFAs. The other three diets were high in total fat $(41 \%)$ and energy $(19.6 \mathrm{~kJ} / \mathrm{g})$. The high-fat diet also used olive oil as the fat source; thus the fatty acid composition was the same as the low-fat diet, but the total fat content was higher. The $\mathrm{HF}^{\mathrm{SFA}}$ contained cocoa butter as the fat source resulting in $62.5 \%$ SFAs, $34.4 \%$ MUFAs and $3 \%$ PUFAs. Finally, the $\mathrm{HF}^{\mathrm{SFA}}$ with added fish oil $\left(\mathrm{HF}^{\mathrm{SFA}+\mathrm{FO}}\right)$ diet also used cocoa butter as the fat source, but was supplemented with menhaden oil, providing $56 \%$ SFAs, 30.4\% MUFAS and 13.6\% PUFAs (Table 1).

Body composition of recipient mice Body weights were measured weekly and total body fat was analysed biweekly (Fig. 1). We observed diet effects on weight gain and adiposity, such that the $\mathrm{HF}^{\mathrm{SFA}+\mathrm{FO}}$ mice gained the most weight and had the greatest total adipose tissue, as well as the largest perigonadal, perirenal and subscapular fat pads $(p<0.005)$ (Table 2). MOTLR ${ }^{-/-}$mice fed low-fat diets tended to weigh less and have less total fat than MOTLR4 ${ }^{+/+}$ mice; however, at death there were no significant differences between recipients of $T l r 4^{+/+}$and $T l r 4^{-1-}$ marrow (Fig. 1a,e). In contrast, the MOTLR4 $4^{--}$mice fed any of the three highfat diets demonstrated modest but non-significant increases in body weight (Fig. 1b-d) and total body fat (Fig. 1f-h)
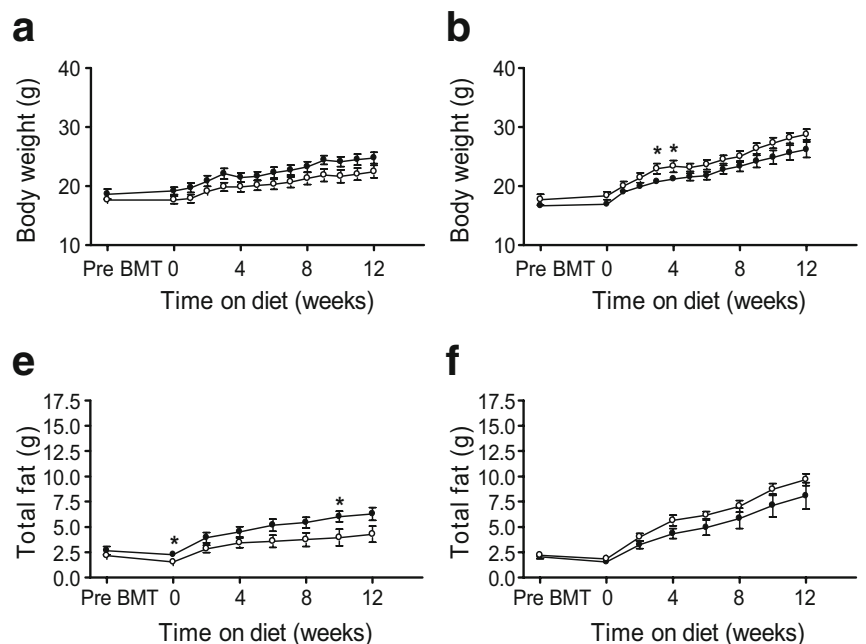

Fig. 1 Total body weight and fat over 12 weeks of diet. Body weight was measured every week and total body fat was measured every other week using NMR in mice that had received either $T l r 4^{+/+}$(black circles) or $T l r 4^{-1-}$ (white symbols) marrow and had been fed low-fat compared with M $\theta$ TLR $4^{+/+}$mice. Upon killing, no significant differences were seen in total body weight, total fat mass or perigonadal, perirenal or subscapular fat pad weight between MOTLR $4^{+/+}$and MOTLR $4^{-/-}$mice on any of the diets (Table 2).

Insulin sensitivity in $H F^{S F A}$ fed mice Euglycaemic-hyperinsulinaemic clamps were performed on mice with or without macrophage TLR4 that were fed the $\mathrm{HF}^{\mathrm{SFA}}$ diet. Arterial glucose levels were clamped at similar levels in both groups (Fig. 2a). Glucose infusion rates required to maintain euglycaemia were not significantly different between the two groups, suggesting similar levels of insulin sensitivity (Fig. 2b). A bolus infusion of 2-deoxy $\left[{ }^{14} \mathrm{C}\right]$ glucose was given during the clamp to determine $R_{\mathrm{g}}$, a measure of tissue glucose uptake. We saw no significant differences in the uptake of glucose in skeletal muscle from mice in the presence or absence of macrophage Tlr4 (Fig. 2c). $R_{\mathrm{g}}$ was also not different in adipose tissue or brain retrieved from MOTLR4 $4^{+/+}$or MOTLR4 $4^{-/-}$mice fed HF ${ }^{\text {SFA }}$ diet (Fig. 2c).

Fatty acid composition of WAT Gas chromatography analyses of WAT revealed that the fatty acid composition of triacylglycerol reflected the dietary fat sources, but was not influenced by the absence of macrophage Tlr4 (ESM Fig. 2). The total triacylglycerol portion of WAT from mice fed the low-fat diet consisted of 21\% SFAs (14:0, 16:0 and 18:0 fatty acids), 73\% MUFAs (16:1 and 18:1 fatty acids) and $6 \%$ PUFAs (18:2 fatty acids). Similarly, WAT from mice fed the high-fat diet contained $16 \%$ SFAs, $77 \%$ MUFAs and 7\% PUFAs. WAT from the HF ${ }^{\text {SFA }}$ fed mice had a slight increase in SFAs and decrease in PUFAs $(25 \%$ SFAs, 72\% MUFAs, 3\% PUFAs). As expected, WAT from
C

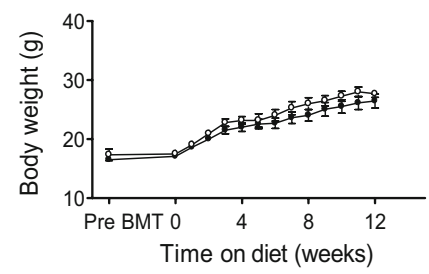

g

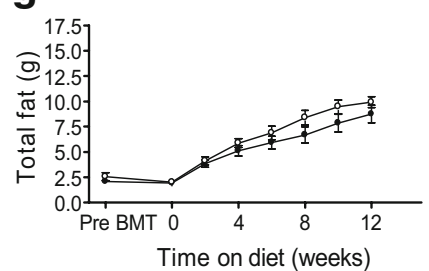

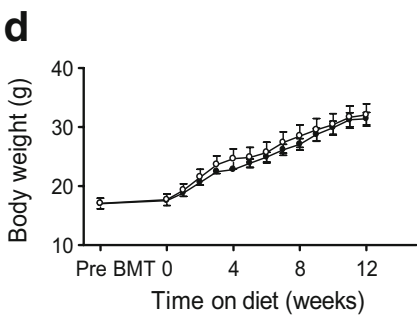

h

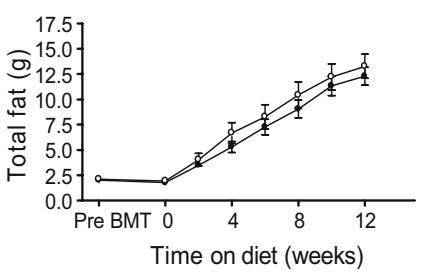

$\operatorname{diet}(\mathbf{a}, \mathbf{e})$, high-fat $\operatorname{diet}(\mathbf{b}, \mathbf{f}), \mathrm{HF}^{\mathrm{SFA}} \operatorname{diet}(\mathbf{c}, \mathbf{g})$ and $\mathrm{HF}^{\mathrm{SFA}+\mathrm{FO}} \operatorname{diet}(\mathbf{d}$, h). Data are expressed as the mean $\pm \operatorname{SEM}(n=5-10$ mice per group). $* p<0.05$ 
Table 2 Body composition of recipient mice after 12 weeks on respective diets

\begin{tabular}{|c|c|c|c|c|c|c|}
\hline \multirow[t]{2}{*}{ Mice } & \multirow[t]{2}{*}{$n$} & \multirow[t]{2}{*}{ Body weight (g) } & \multirow[t]{2}{*}{ Total fat (g) } & \multicolumn{3}{|l|}{ Fat pads } \\
\hline & & & & Perigonadal (g) & Perirenal (g) & Subscapular (g) \\
\hline \multicolumn{7}{|l|}{ Low-fat diet } \\
\hline $\mathrm{M} \theta \mathrm{TLR} 4^{+/+}$ & 8 & $25 \pm 1$ & $6.3 \pm 0.6$ & $0.81 \pm 0.10$ & $0.31 \pm 0.04$ & $0.07 \pm 0.01$ \\
\hline M $\theta \mathrm{TLR}_{4}^{-/-}$ & 6 & $22 \pm 1$ & $4.3 \pm 0.8$ & $0.52 \pm 0.08$ & $0.23 \pm 0.07$ & $0.06 \pm 0.01$ \\
\hline \multicolumn{7}{|l|}{ High-fat diet } \\
\hline $\mathrm{M} \theta \mathrm{TLR}^{+/+}$ & 8 & $26 \pm 1$ & $8.1 \pm 1.3^{\mathrm{a}}$ & $1.01 \pm 0.17^{\mathrm{b}}$ & $0.50 \pm 0.11^{\mathrm{a}}$ & $0.08 \pm 0.01$ \\
\hline M $\theta \mathrm{TLR}_{4}^{-/-}$ & 5 & $29 \pm 1$ & $9.7 \pm 0.6^{\mathrm{a}}$ & $1.30 \pm 0.08^{\mathrm{b}}$ & $0.66 \pm 0.20^{\mathrm{a}}$ & $0.09 \pm 0.01$ \\
\hline \multicolumn{7}{|l|}{$\mathrm{HF}^{\mathrm{SFA}}$ diet } \\
\hline MOTLR4 $4^{+/+}$ & 10 & $26 \pm 1$ & $8.7 \pm 0.9^{b}$ & $1.04 \pm 0.10^{\mathrm{a}}$ & $0.59 \pm 0.07^{\mathrm{a}}$ & $0.10 \pm 0.01$ \\
\hline MOTLR4 $4^{-/-}$ & 6 & $28 \pm 1$ & $9.9 \pm 0.5^{\mathrm{b}}$ & $1.15 \pm 0.08^{\mathrm{a}}$ & $0.57 \pm 0.06^{\mathrm{a}}$ & $0.09 \pm 0.02$ \\
\hline \multicolumn{7}{|l|}{$\mathrm{HF}^{\mathrm{SFA}+\mathrm{FO}}$ diet } \\
\hline MOTLR4 ${ }^{+/+}$ & 9 & $31 \pm 1^{\mathrm{e}}$ & $12.3 \pm 0.9^{\mathrm{e}}$ & $1.61 \pm 0.12^{\mathrm{f}}$ & $0.79 \pm 0.09^{c}$ & $0.14 \pm 0.02^{\mathrm{d}}$ \\
\hline M $\theta T_{L R} 4^{-/-}$ & 6 & $32 \pm 1^{\mathrm{e}}$ & $13.3 \pm 1.2^{\mathrm{e}}$ & $1.74 \pm 0.12^{\mathrm{f}}$ & $0.81 \pm 0.06^{\mathrm{c}}$ & $0.13 \pm 0.01^{\mathrm{d}}$ \\
\hline
\end{tabular}

Data are mean $\pm \operatorname{SEM}(n=5-10$ mice per group)

Body composition was measured after mice were fed their respective diets for 12 weeks

Student's $t$ test revealed no significant differences between MOTLR $4^{+/+}$and MOTLR $4^{-1-}$ mice. Two-way ANOVA revealed a main effect for diets for all weights listed $(p<0.00001)$. There were no significant main effects for macrophage TLR4 genotype

Significant findings of post hoc tests were as indicated: ${ }^{\mathrm{a}} p<0.05,{ }^{\mathrm{b}} p<0.005,{ }^{\mathrm{c}} p<0.0001$ for diet compared with low fat; ${ }^{\mathrm{d}} p<0.05$, ${ }^{\mathrm{e}} p<0.005$, ${ }_{p}^{\mathrm{f}}<<0.0005$ for diet compared with all other diets

a

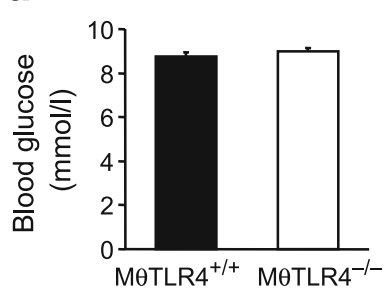

b

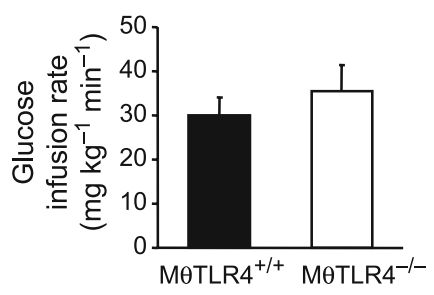

C

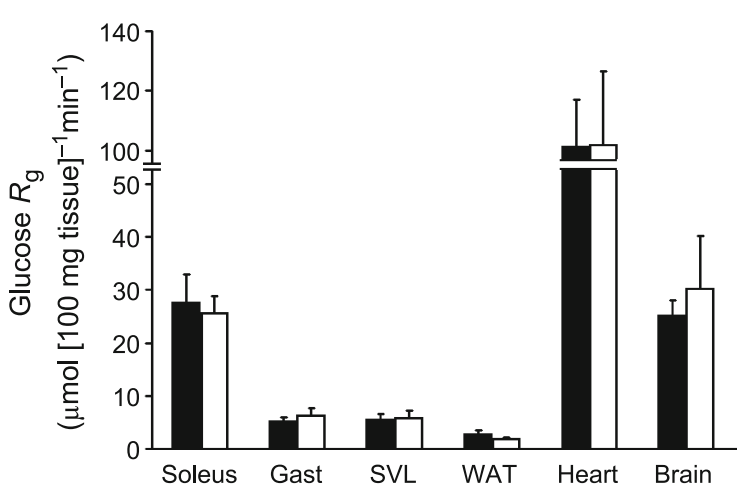

Fig. 2 Euglycaemic-hyperinsulinaemic clamps in $\mathrm{HF}^{\mathrm{SFA}}$ fed mice. Blood glucose levels (a), average glucose infusion rate during the steady-state period ( 80 to $120 \mathrm{~min}$ ) (b) and tissue-specific glucose metabolic index $\left(R_{\mathrm{g}}\right)(\mathbf{c})$ during a 120-min euglycaemic-hyperinsulinaemic clamp in chronically catheterised, conscious MOTLR4 ${ }^{+/+}$ (black bars) and M $\theta \mathrm{TLR}^{-{ }^{--}}$(white bars) mice fed a $\mathrm{HF}^{\mathrm{SFA}}$ diet. Mice were fasted for $5 \mathrm{~h}$ before the experiment. Data are mean \pm SEM for ( $n=4-5$ mice per group). Gast gastrocnemius muscle, $S V L$ superficial vastus lateralis mice fed $\mathrm{HF}^{\mathrm{SFA}+\mathrm{FO}}$ diet were the only ones to contain the long-chain PUFAs eicosapentaenoic acid (20:5) and docosahexaenoic acid (22:6), while displaying 33\% SFAs, 60\% MUFAs and 7\% PUFAs (18:2, 20:4, 20:5, 22:5 and 22:6 fatty acids).

Plasma variables of recipient mice After 12 weeks on their respective diets, plasma was collected from overnight fasted mice and used to analyse total cholesterol, total triacylglycerol, NEFA, glucose, insulin and leptin levels (Table 3). Because of the high cholesterol content of all the diets and the $L d r l$ deficiency of recipient mice, plasma lipids were elevated by all four diets. Dietary effects were observed for the degree of hyperlipidaemia $(p<0.001)$, with the $\mathrm{HF}^{\mathrm{SFA}+\mathrm{FO}}$ mice having the lowest total cholesterol and NEFA levels. NEFA levels were also significantly lower in the $\mathrm{HF}^{\mathrm{SFA}}$ group than in the high-fat and low-fat groups. Blood glucose levels were highest in $\mathrm{HF}^{\mathrm{SFA}}$ and $\mathrm{HF}^{\mathrm{SFA}+\mathrm{FO}}$ fed mice. Likewise, plasma insulin levels were significantly higher in these groups than in the groups fed low-fat and high-fat diets $(p<0.01)$. Finally, in agreement with the increased body weight and adiposity, leptin levels were highest in the $\mathrm{HF}^{\mathrm{SFA}+\mathrm{FO}}$ groups $(p<0.00001)$. Despite these main effects of the different diets, we saw no significant differences in any of the plasma variables between MOTLR $4^{+/+}$and MOTLR $4^{-/-}$mice on any of the diets.

Macrophage accrual in adipose tissue of recipient mice Paraffin sections of perigonadal WAT from MOTLR $4^{+/+}$ and MOTLR4 ${ }^{-/-}$mice stained with an antibody for the macrophage surface marker F4/80 demonstrated no overt 
Table 3 Plasma variables of recipient mice at death

\begin{tabular}{|c|c|c|c|c|c|c|c|}
\hline Mice & $n$ & $\begin{array}{l}\text { Cholesterol } \\
(\mathrm{mmol} / \mathrm{l})\end{array}$ & $\begin{array}{l}\text { Triacylglycerol } \\
(\mathrm{mmol} / \mathrm{l})\end{array}$ & $\begin{array}{l}\text { NEFA } \\
(\mathrm{mEq} / \mathrm{l})\end{array}$ & $\begin{array}{l}\text { Glucose } \\
(\mathrm{mmol} / \mathrm{l})\end{array}$ & $\begin{array}{l}\text { Insulin } \\
(\mathrm{pmol} / \mathrm{l})\end{array}$ & $\begin{array}{l}\text { Leptin } \\
(\mathrm{ng} / \mathrm{ml})\end{array}$ \\
\hline \multicolumn{8}{|l|}{ Low fat } \\
\hline M $\theta$ TLR4 $4^{+/+}$ & 8 & $23.0 \pm 1.2$ & $2.5 \pm 0.4$ & $1.42 \pm 0.18$ & $3.5 \pm 0.3$ & $44.7 \pm 8.6$ & $10 \pm 2$ \\
\hline $\mathrm{M} \theta \mathrm{TLR} 4^{-/-}$ & 6 & $21.0 \pm 1.2$ & $2.1 \pm 0.4$ & $1.42 \pm 0.18$ & $3.9 \pm 0.4$ & $36.1 \pm 6.9$ & $7 \pm 1$ \\
\hline \multicolumn{8}{|l|}{ High fat } \\
\hline${\text { M } \theta T L R 4^{+/+}}^{-1}$ & 8 & $17.9 \pm 2.6$ & $2.5 \pm 0.3$ & $1.36 \pm 0.13$ & $3.6 \pm 0.3$ & $43.0 \pm 6.9$ & $23 \pm 5$ \\
\hline $\mathrm{M} \theta \mathrm{TLR} 4^{-/-}$ & 5 & $20.0 \pm 2.1$ & $2.3 \pm 0.1$ & $1.47 \pm 0.17$ & $4.2 \pm 0.3$ & $36.1 \pm 5.2$ & $24 \pm 1$ \\
\hline \multicolumn{8}{|l|}{$\mathrm{HF}^{\mathrm{SFA}}$} \\
\hline M $\theta$ TLR $4^{+/+}$ & 10 & $18.6 \pm 1.1$ & $2.7 \pm 0.2$ & $1.00 \pm 0.05^{\mathrm{b}}$ & $5.2 \pm 0.3^{\mathrm{b}}$ & $94.7 \pm 17.2^{\mathrm{c}}$ & $26 \pm 3^{\mathrm{a}}$ \\
\hline M $\theta$ TLR $4^{-/-}$ & 6 & $18.7 \pm 1.2$ & $2.5 \pm 0.2$ & $1.08 \pm 0.03^{\mathrm{b}}$ & $5.9 \pm 1.2^{\mathrm{b}}$ & $87.8 \pm 17.2^{\mathrm{c}}$ & $30 \pm 3^{\mathrm{a}}$ \\
\hline \multicolumn{8}{|l|}{$\mathrm{HF}^{\mathrm{SFA}+\mathrm{FO}}$} \\
\hline $\mathrm{M} \theta \mathrm{TLR}_{4}^{+/+}$ & 9 & $13.6 \pm 1.4^{\mathrm{d}}$ & $2.0 \pm 0.2$ & $1.04 \pm 0.04^{\mathrm{b}}$ & $5.5 \pm 0.4^{\mathrm{c}}$ & $117.0 \pm 18.9^{\mathrm{c}}$ & $54 \pm 11^{\circ}$ \\
\hline M $\theta$ TLR $4^{-/-}$ & 6 & $15.4 \pm 1.9^{\mathrm{d}}$ & $2.1 \pm 0.3$ & $1.01 \pm 0.09^{\mathrm{b}}$ & $6.5 \pm 0.4^{\mathrm{c}}$ & $96.4 \pm 13.8^{\mathrm{c}}$ & $64 \pm 6^{\mathrm{d}}$ \\
\hline
\end{tabular}

Data are mean $\pm \operatorname{SEM}(n=5-10$ mice per group $)$

Plasma variables were measured after recipient mice were fed their respective diets for 12 weeks. Mice were fasted overnight before killing and plasma collection

Student's $t$ tests revealed no significant differences among MOTLR $4^{+/+}$and M $\theta$ TLR $4^{-/-}$groups for each diet. Two-way ANOVA revealed main effect for diet for cholesterol $(p<0.001)$, NEFA $(p<0.001)$, glucose $(p<0.0001)$, insulin $(p<0.0001)$ and leptin $(p<0.00001)$. Main effects for macrophage Tlr 4 genotype reached near significance for glucose $(p=0.07)$

Significant findings of post hoc tests were as indicated:

${ }^{\mathrm{a}} p<0.05$ for diet compared with low fat, ${ }^{\mathrm{b}} p<0.05,{ }^{\mathrm{c}} p<0.01$ for diet compared with low fat and high fat; ${ }^{\mathrm{d}} p<0.00001$ for diet compared with all other diets

differences between MOTLR4 ${ }^{+/+}$and M $\theta T L R 4^{-/-}$mice (Fig. 3a-h). However, quantitative analysis of mRNA expression of F4/80 (also known as Emrl) in adipose tissue revealed that when on the low-fat diet, MOTLR $4^{-/}$ mice had significantly less $F 4 / 80$ gene expression than M $\theta \mathrm{TLR}^{+/+}$mice (Fig. 3i; $p<0.05$ ). The M $\theta \mathrm{TLR} 4^{-/-}$mice also demonstrated a trend toward a reduction in $C d 68$ expression (Fig. 3m). This difference was not seen in mice challenged with any of the three high-fat diets (Fig. 3j-1, $\mathrm{n}-\mathrm{p})$.

Adipose tissue inflammation of recipient mice To determine the inflammatory status of adipose tissue in response to the presence or absence of macrophage Tlr4, real-time RT-PCR was used to analyse gene expression of several inflammatory genes. Dietary effects were seen for both Mip-1 $\alpha$ (also known as $C c l 3$ ) and $S a a$, whereby the $\mathrm{HF}^{\mathrm{SFA}+\mathrm{FO}}$ mice had significantly greater expression of these inflammatory genes than the low-fat and $\mathrm{HF}^{\mathrm{SFA}}$ groups $(p<0.05)$. Comparisons between MOTLR4 ${ }^{-/-}$mice and MOTLR4 ${ }^{+/+}$ mice demonstrated that Mip-1 $\alpha$ mRNA levels were significantly lower in M $\theta \mathrm{TLR} 4^{-/-}$than in M $\theta \mathrm{TLR} 4^{+/+}$ mice when fed a low-fat diet $(p<0.05)$ (Fig. 4a). Similarly, Saa3 and Tlr4 expression levels were reduced in MOTLR4 ${ }^{-/-}$mice $(p<0.01)$ (Fig. $\left.4 \mathrm{e}, \mathrm{i}\right)$. When mice were challenged with any of the three high-fat diets, there were no significant differences in Mip-1 $\alpha$ (Fig. 4b-d), Saa3 (Fig. 4f-h) or Tlr4 (Fig. 4j-l) mRNA levels among MOTLR $4^{-/-}$mice and MOTLR ${ }^{+/+}$mice.
Classical versus alternative macrophage marker phenotype of adipose tissue from mice fed low-fat diet To further characterise the macrophages present in adipose tissue, the gene expression of classical macrophage markers (M1) versus alternative activation macrophage markers (M2) was assessed by real-time RT-PCR in perigonadal fat pads. The $\mathrm{HF}^{\mathrm{SFA}+\mathrm{FO}}$ mice demonstrated a significant dietary effect by displaying elevated levels of both M1 and M2 compared with mice fed the other diets (data not shown). There were no significant differences in expression of M1 markers such as Tnf- $\alpha$ (also known as Tnf), Il-12 (also known as Ill2), monocyte chemoattractant protein-1 and inducible nitric oxide synthase or M2 markers such as arginase, mannose receptor, macrophage galactose $\mathrm{N}$-acetyl-galactosamine specific lectin $1(M g l 1)$ and $M g l 2$ in mice with or without MOTLR4 that were on a low-fat diet (Fig. 5).

Atherosclerotic lesion area of recipient mice To quantify atherosclerotic lesion area, hearts were sectioned at the aortic root and neutral lipids were stained with Oil-Red-O (Fig. 6a-h). The mice fed the low-fat diet displayed the largest lesion areas (Fig. 6i) compared with mice fed the high-fat diets (Fig. 6j-1). In accordance with their reduced plasma lipid levels, mice fed the $\mathrm{HF}^{\mathrm{SFA}+\mathrm{FO}}$ diet were protected from atherosclerotic lesion development (Fig. 61). In mice on low-fat diet, M $\theta$ TLR $4^{-1-}$ mice demonstrated smaller lesions $\left(130,998 \pm 15,719 \mu^{2}\right)$ than MOTLR4 ${ }^{+/+}$ mice $\left(176,856 \pm 11,671 \mu \mathrm{m}^{2} ; p<0.05\right)$ (Fig. 6i). There were no significant differences in lesion areas between mice with 

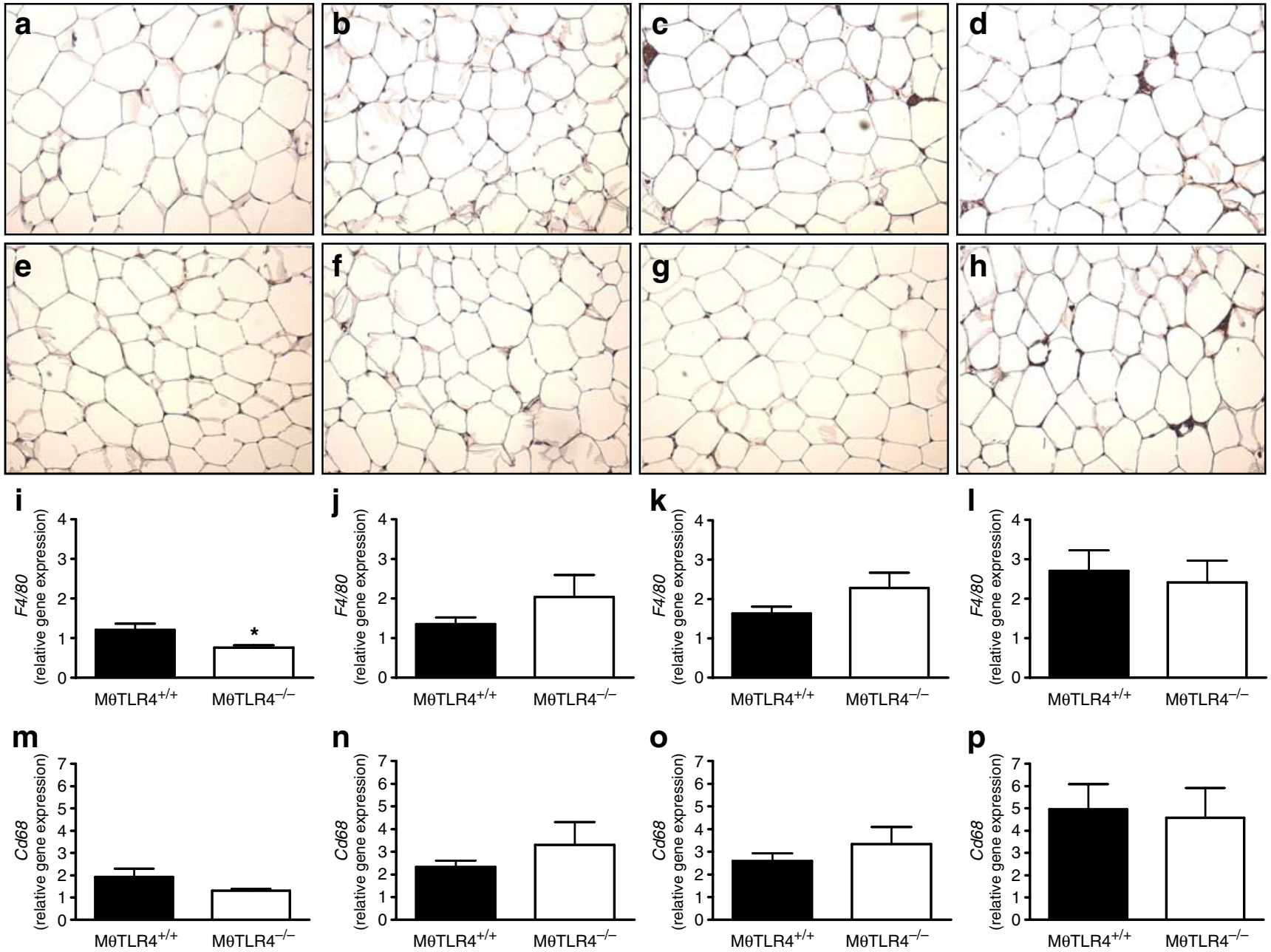

Fig. 3 F4/80 staining and macrophage expression in adipose tissue. WAT sections from mice fed low fat $(\mathbf{a}, \mathbf{e})$, high fat $(\mathbf{b}, \mathbf{f}), \mathrm{HF}^{\mathrm{SFA}}(\mathbf{c}, \mathbf{g})$ and $\mathrm{HF}^{\mathrm{SFA}+\mathrm{FO}}(\mathbf{d}, \mathbf{h})$ diets were immunostained with an antibody for F4/80, a macrophage surface marker. Images are shown at $\times 10$ magnification for mice receiving $T l r 4^{+/+}(\mathbf{a}-\mathbf{d})$ and $T l r 4^{-/-}(\mathbf{e}-\mathbf{h})$ marrow. RNA was isolated from the perigonadal fat pads and real-time RT-PCR was used to determine F4/80 expression (i-l) and Cd68

or without macrophage Tlr4 that were fed the high-fat diets (Fig. 6j-1).

\section{Discussion}

Our results support the possibility of a role for macrophage Tlr4 in regulating ATM content and inflammation in the presence of low-fat diet feeding. Despite an absence of differences in body weight, total fat or perigonadal fat pad weight, M $\theta \mathrm{TLR}^{-/-}$mice fed a diet low in total fat displayed decreased ATM accumulation as evidenced by F4/80 mRNA expression (Fig. 3). MOTLR4 ${ }^{-1-}$ mice also exhibited decreased local inflammation with significantly lower Mip-1 $\alpha$ and Saa3 expression levels in WAT (Fig. 4), although significant differences were not detected for other

expression $(\mathbf{m}-\mathbf{p})$ from mice on their respective diets. Black bars, mice receiving $T l r 4^{+/+}$marrow; white bars, mice receiving $T l r 4^{-1-}$ marrow. Data are expressed as mean $\pm \operatorname{SEM}$ ( $n=5-10$ mice per group). Two-way ANOVA revealed a main effect for diets for $F 4 / 80(p<0.001)$ and $C d 68 \quad(p<0.005)$. There were no significant main effects for macrophage Tlr4 genotype. Significant findings of post hoc tests: $* p<0.05$

inflammatory markers tested (Fig. 5). These data support a capacity for macrophage Tlr 4 in regulating macrophage accumulation and inflammation in WAT, even in the absence of differences in body weight and adipose tissue mass. In addition, our studies are the first to demonstrate that deficiency of macrophage Tlr4 can protect against atherosclerotic lesion formation.

Several studies have investigated the effects of global TLR4 deficiency on body composition, adipose tissue physiology, inflammation and insulin resistance in vivo $[18,23-25,31]$. These investigators found that the absence of whole-body TLR4 results in a significant decrease in inflammation and insulin resistance; however, conflicting results with regard to body weight and fat gain, as well as ATM accumulation, have been reported [18, 23-25, 31]. Similar to studies involving global Tlr4 deletions [18], our 
a

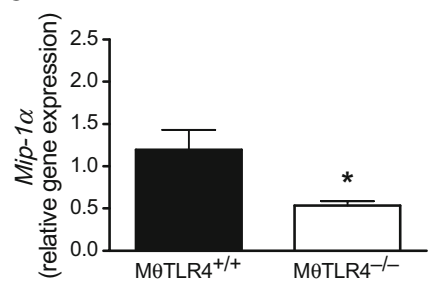

e

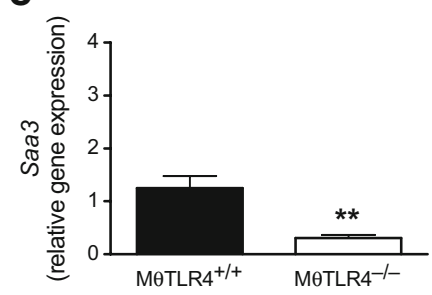

i

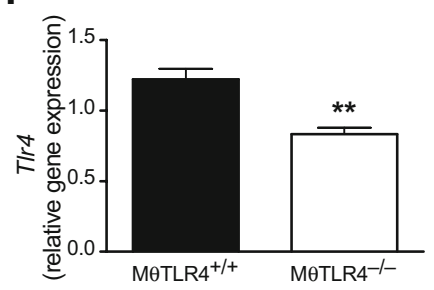

b

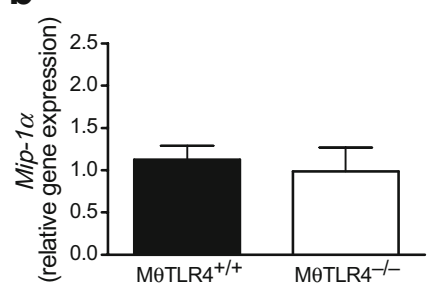

f

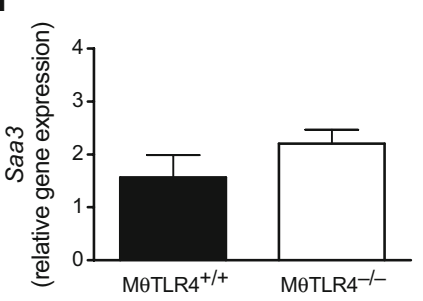

j

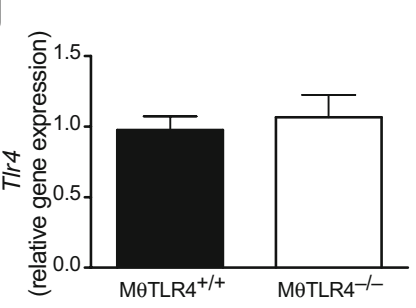

Fig. 4 Inflammation in WAT. Local inflammation was determined in WAT by analysing gene expression using real-time RT-PCR. Mip- $1 \alpha$ (a-d), Saa3 (e-h) and Tlr4 (i-l) mRNA expression were measured in mice fed their respective diets (low fat $\mathbf{a}, \mathbf{e}, \mathbf{i}$; high fat $\mathbf{b}, \mathbf{f}, \mathbf{j} ; \mathrm{HF}^{\mathrm{SFA}} \mathbf{c}$, g, k; $\left.\mathrm{HF}^{\mathrm{SFA}+\mathrm{FO}} \mathbf{d}, \mathbf{h}, \mathbf{l}\right)$ Data are expressed as mean \pm SEM $(n=5-10$

results involving macrophage Tlr4 deletion were specific to female mice, suggesting a sexual dimorphism in the effects of macrophage Tlr4. Our studies also demonstrate that dietary fat can modulate metabolic responses to macrophage Tlr4 deficiency.

Previous reports have established that in the absence of whole-body TLR4, mice fed high-fat diets or subjected to lipid infusion are protected against insulin resistance as evidenced by glucose tolerance tests, insulin signalling and euglycaemic-hyperinsulinaemic clamps [18, 23-25]. Because SFAs are the key ligands for TLR4, our current studies investigated the more specific question of the effect of macrophage Tlr 4 on insulin sensitivity in the presence of a high-fat diet rich in SFAs. However, using highly sensitive euglycaemic-hyperinsulinaemic clamp techniques, we demonstrated that macrophage Tlr4 exerts little to no effect on insulin sensitivity when this mouse model is challenged with a $\mathrm{HF}^{\mathrm{SFA}}$ diet (Fig. 2).

While our results provide evidence supporting a role for macrophage Tlr4 in ATM content and inflammation, these effects were apparent only in the context of low-fat diet feeding and were only moderate. There are several reasons why the impact of high-fat diet feeding may not have been affected by macrophage Tlr4 deficiency in this model

C

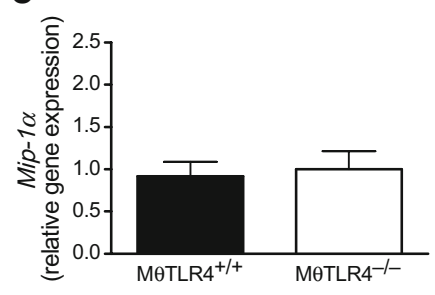

d

g

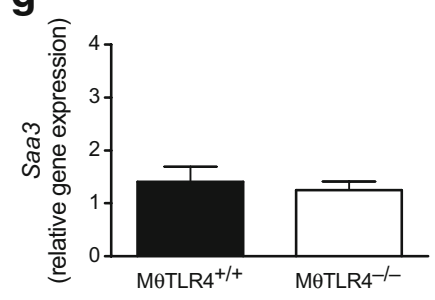

h
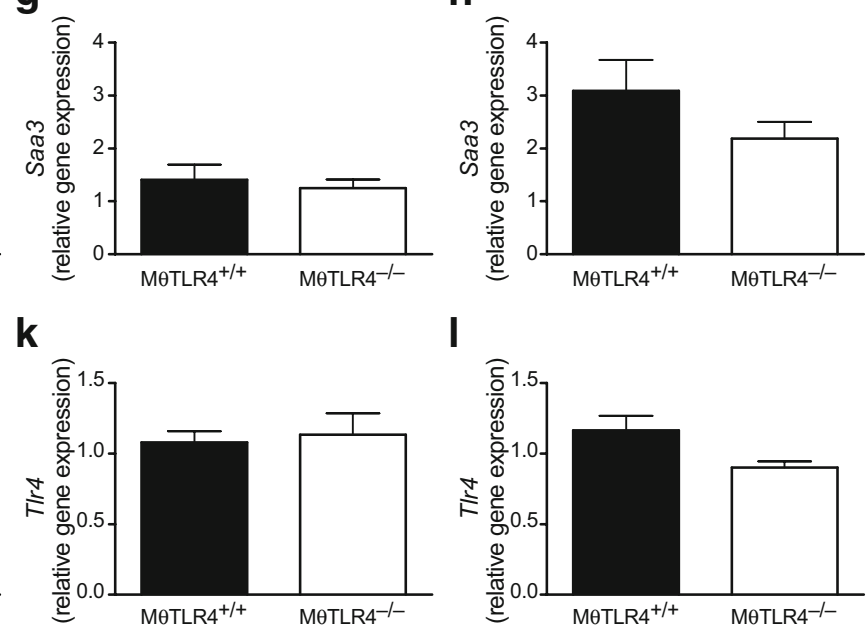

I

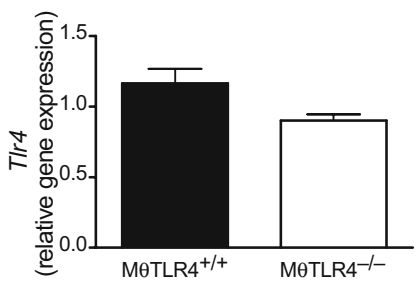

mice per group). Two-way ANOVA revealed a main effect for diets for Mip-1 $\alpha \quad(p<0.05)$ and Saa3 $(p<0.00001)$. Main effects for macrophage Tlr4 genotype reached near significance for Tlr4 expression $(p=0.08)$. Significant findings of post hoc tests: ${ }^{*} p<0.05$, $* * p<0.01$

system. First, it is possible that in the presence of a high-fat diet, the system is challenged to a point that subtle differences in ATM content are no longer detected when only macrophage Tlr4 expression is different between groups. Furthermore, dietary cholesterol itself can contribute to macrophage accumulation in WAT [32], while the interaction between dietary cholesterol and fatty acids is unexplored. Second, our studies used bone marrow transplantation, which results in suppression of body weight gain and fat expansion and could have influenced the results in our high-fat diet groups. Third, the source and type of SFAs are also important. In our studies, we used cocoa butter as a fat source rich in SFAs. Cocoa butter is almost solely composed of SFAs; however, they are medium-chain SFAs that are absorbed and metabolised differently than long-chain SFAs, which are more prominent in animal fat sources. Fourth, because we were also interested in atherosclerotic lesion development, we performed these studies in $\mathrm{Ldlr}^{-1-}$ mice. It is possible that the LDLR is also important for dietary fatty acid interactions and may influence macrophage recruitment. Fifth and lastly, it should also be noted that $\mathrm{A}^{\mathrm{y}} / \mathrm{a}$ mice develop adult-onset obesity due to hyperphagia resulting from ectopic expression of the agouti protein that acts as an 
a

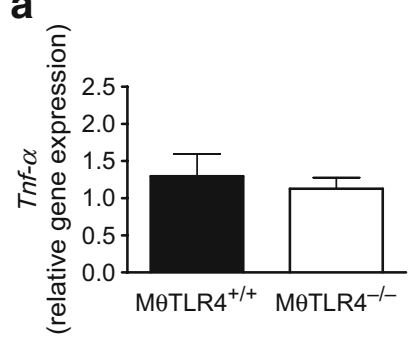

C

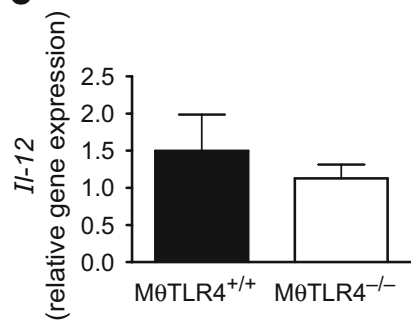

e
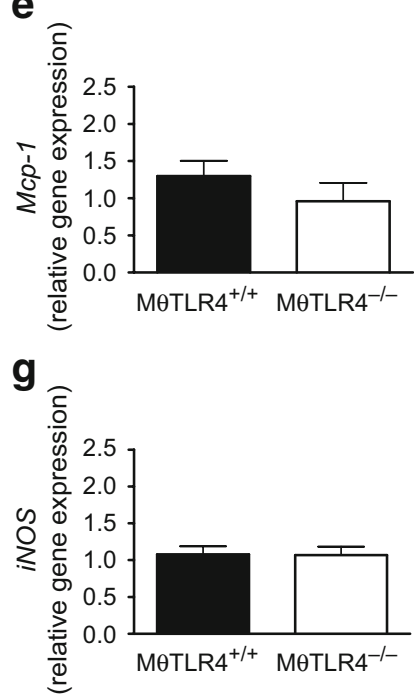

b
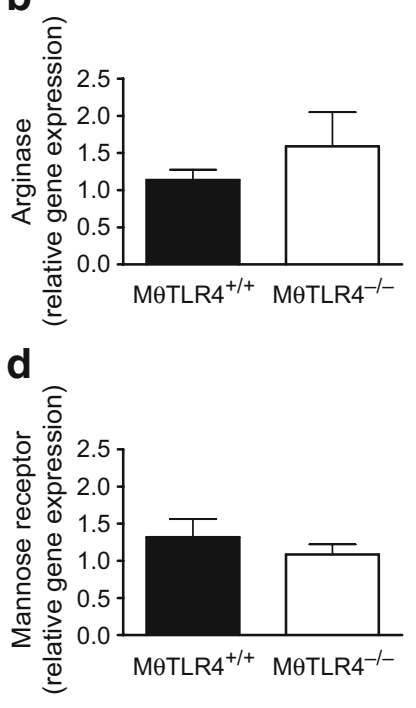

f

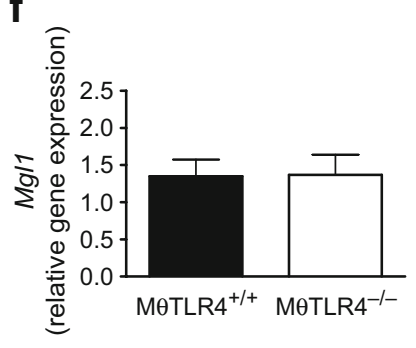

h

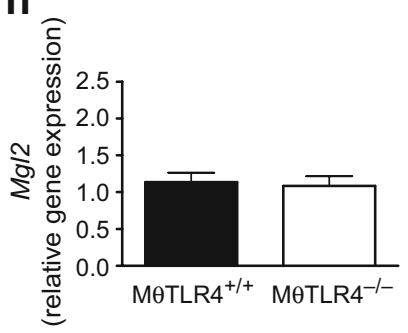

Fig. 5 M1 and M2 classification of ATMs. Markers of M1 and M2 macrophages were determined in WAT by analysing gene expression. M1: a Tnf- $\alpha$, c Il-12, e Mcp- 1 and $\mathbf{g} i N o s$, and for M2 macrophages. M2: b arginase, $\mathbf{d}$ mannose receptor, $\mathbf{f} M g l l$ and $\mathbf{h} M g l 2$. Black bars, mice receiving $\mathrm{Tlr} 4^{+/+}$marrow; white bars, mice receiving $\mathrm{Tlr}^{-4^{-1}}$ marrow. Data are shown only from mice fed the low-fat diet and are expressed as mean \pm SEM ( $n=5-10$ mice per group)

antagonist of the melanocortin 4 receptor $[33,34]$. Thus, it cannot be ruled out that the effects of ectopic expression of the agouti protein might influence results seen in this mouse model. Although more work is required to understand the role of macrophage Tlr4 in macrophage recruitment to WAT and the artery wall, our data demonstrate that the absence of macrophage Tlr 4 exerts effects on macrophage accrual under certain dietary conditions.

Not only is macrophage content in WAT important, the classification of macrophages provides an indication of their activation status. M1 polarised macrophages are

pro-inflammatory, while M2 polarised macrophages are anti-inflammatory. We had anticipated that absence of macrophage Tlr 4 might cause WAT from M $\theta \mathrm{TLR}^{-/-}$mice to have lower expression of M1 markers and higher expression of M2 markers; however, our results revealed no differences between MOTLR $4^{+/+}$and MOTLR $4^{-/-}$mice (Fig. 5). Thus, in this mouse model, expression of Tlr 4 by ATMs does not appear to influence the recruitment of one type of macrophage over another (M1 vs M2), although inflammatory markers such as Mip-1 $\alpha$ and Saa were reduced in WAT of MOTLR4 ${ }^{-1-}$ mice. While our data do not suggest a role for macrophage Tlr4 in M1 versus M2 phenotype in WAT in this model, a role of Tlr4 in general in M1/M2 responses cannot be ruled out considering the importance of both Tlr4 and M1/M2 classification in the initiation of an inflammatory response.

We have previously demonstrated that fish oil supplementation of an olive oil-based diet increases body fat mass and decreases plasma lipids, atherosclerosis, ATMs and inflammation in $\mathrm{Ldlr}^{-/-}$mice [35]. In the current study, feeding of the BMT recipient $\mathrm{A}^{\mathrm{y} / \mathrm{a} ; L d l r^{--}}$mice with the $\mathrm{HF}^{\mathrm{SFA}+\mathrm{FO}}$ diet resulted in many of the same outcomes, with the exception of beneficial effects in WAT. In fact, $\mathrm{HF}^{\mathrm{SFA}+\mathrm{FO}}$ feeding appeared to induce the greatest amount of inflammatory macrophage accumulation in WAT (Fig. 4). The differences between these two studies could be explained by the base fat source of the diet, the effect of BMT or the extent of obesity between the two models. Taken together our studies demonstrate that fish oil supplementation has beneficial effects on plasma lipids and atherogenesis regardless of the other components of the diet, but that it cannot ameliorate metabolic disorders related to adipose tissue when the diet is also rich in SFAs. This is an important distinction when considering supplementation with fish oil for the treatment of metabolic diseases.

Several studies have suggested a role for TLR4 in atherosclerotic lesion area development in mice [36-39]. In addition, patients heterozygous or homozygous for two single nucleotide polymorphisms (Asp ${ }^{299}$ Gly and $\mathrm{Thr}^{399} \mathrm{Ile}$ ) are hyporesponsive to TLR 4 activation and as a result are less susceptible to atherosclerosis [40-42]. Our studies show the novel finding that $\mathrm{A}^{\mathrm{y}} / \mathrm{a} ; \mathrm{Ldll}^{-/-}$mice fed a diet low in total fat supplemented with cholesterol develop smaller lesions in the absence of macrophage Tlr4. These effects were lost when the mice were challenged with any of the three high-fat diets. Previous work from our laboratory has shown that while hyperlipidaemia was critical in macrophage influx into the artery wall, obesity was a better predictor of macrophage entrenchment in WAT [26, 27]. The current studies suggest that macrophage Tlr4 plays a definitive role in macrophage entry into the artery wall and WAT, providing a commonality in mechanisms of macrophage recruitment to these two tissues. 

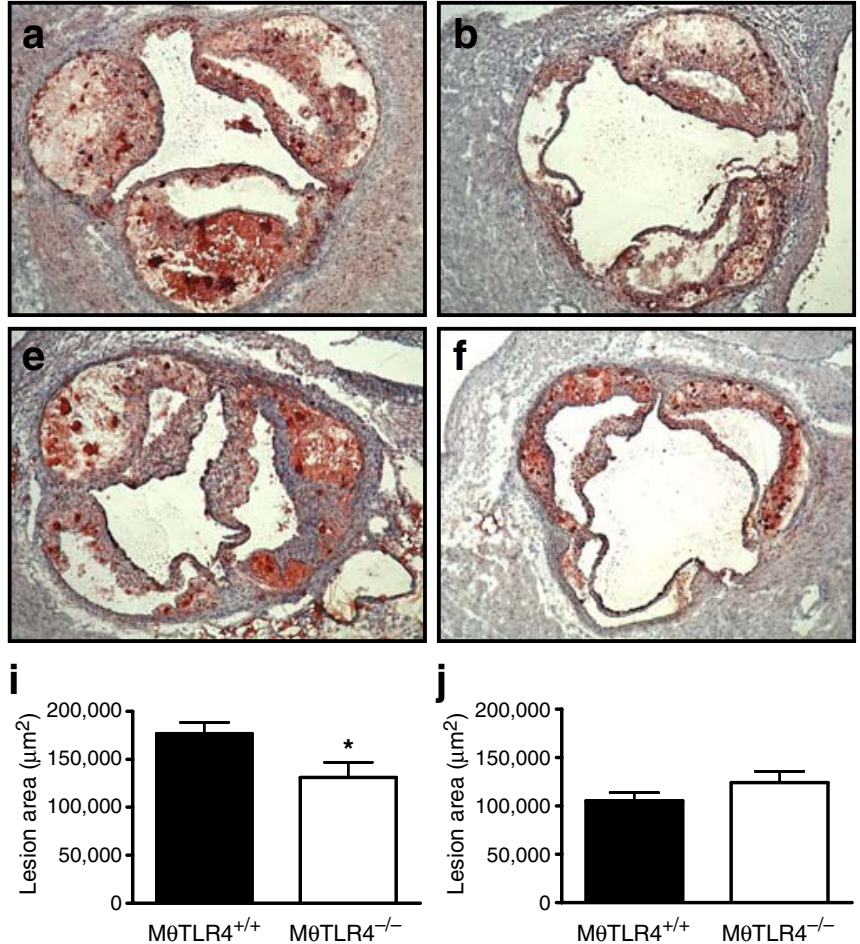

Fig. 6 Quantification of lesion area. Hearts were sectioned at the aortic root and atherosclerotic lesions were stained using Oil-Red-O for low fat $(\mathbf{a}, \mathbf{e})$, high fat $(\mathbf{b}, \mathbf{f}), \mathrm{HF}^{\mathrm{SFA}}(\mathbf{c}, \mathbf{g})$ and $\mathrm{HF}^{\mathrm{SFA}+\mathrm{FO}}(\mathbf{d}, \mathbf{h})$ diets. Images are shown at $\times 10$ magnification for mice receiving $\mathrm{Tlr}^{+/+}$

The low-fat diet was low in total fat, yet mice fed this diet displayed the highest plasma lipid levels (Table 3) and greatest atherosclerotic lesion areas (Fig. 6). While the lowfat diet was low in total fat, all of the diets contained equal amounts of added cholesterol and sucrose. The added cholesterol and high carbohydrates are likely to have contributed to the resulting hyperlipidaemia and large atherosclerotic lesions seen in animals fed the low-fat diet. A similar effect was recently noted by Hartvigsen and colleagues, who showed that a diet high in cholesterol but low in fat caused hyperlipidaemia and atherosclerotic lesion formation in $\mathrm{Ldlr}^{--}$mice [43]. Together, our data suggest that complex interactions exist between dietary levels of total fat, fatty acid composition, cholesterol and sucrose, resulting in differences in plasma lipids and atherosclerosis (Table 3, Fig. 6).

Our current studies establish a potential role for macrophage TLR4 in metabolic diseases such as obesity and cardiovascular disease. Macrophage Tlr4 deletion protects against macrophage accumulation in WAT and the resulting pro-inflammatory response that follows, as well as macrophage accumulation in the artery wall and the resulting formation of atherosclerotic lesions. These results suggest a specific capacity for macrophage Tlr4 to influence macrophage accrual and inflammation in pathological conditions related to obesity.
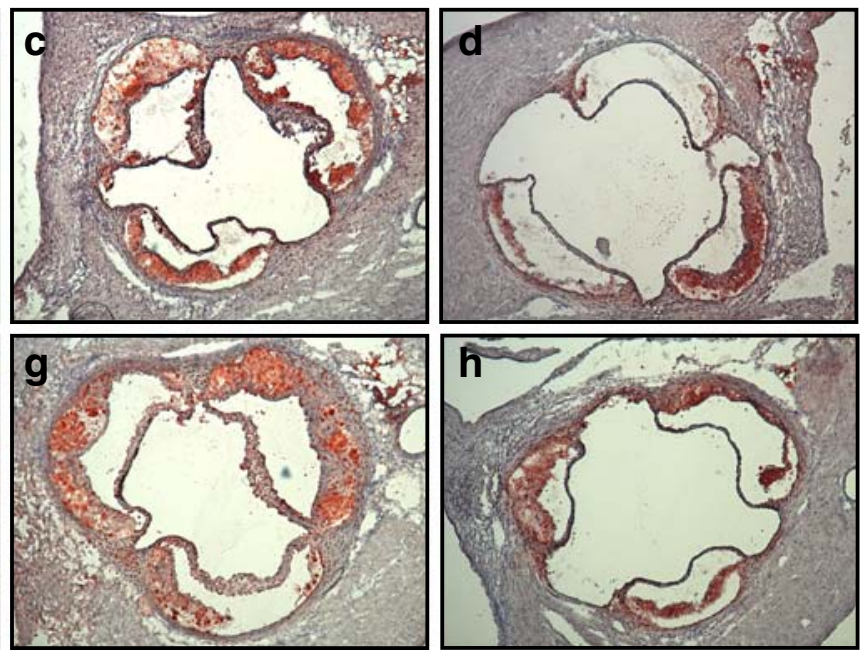

k
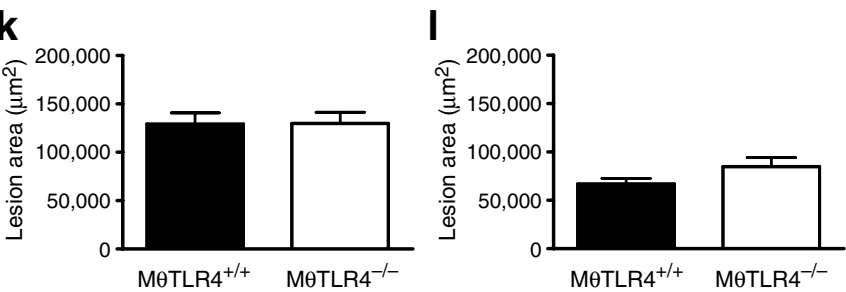

(a-d) and $T l r 4^{-1-}$ (e-h) marrow. Lesion areas were quantified using Kinetic Histometrix software $(n=5-10$ mice per group): low-fat (i), high-fat $(\mathbf{j}), \mathrm{HF}^{\mathrm{SFA}}(\mathbf{k})$ and $\mathrm{HF}^{\mathrm{SFA}+\mathrm{FO}}(\mathbf{l})$. Data are presented as mean \pm SEM. ${ }^{*} p<0.05$

Acknowledgements This work was supported by a Pilot \& Feasibility Award from the Vanderbilt Digestive Diseases Research Centre (VDDRC, DK058404) to A. H. Hasty and by NIH grants R01HL089466 and DK54902. This work was also supported by a predoctoral fellowship awarded to K. R. Coenen by the AHA (0715090B) and an American Diabetes Association mentor-based post-doctoral fellowship grant to R. Lee-Young. M. J. Puglisi and K. R. Coenen were supported by the Vanderbilt Molecular Endocrinology Training Program (NIH T32DK07563). Insulin, leptin and fatty acid analysis were performed in the Analytical Services Core of the Diabetes Research and Training Centre (DK20593)/ Vanderbilt Mouse Metabolic Phenotyping Centre (DK59637). We received assistance from the Cell Imaging Core of the VDDRC (DK058404) for the immunohistochemical analyses. In addition, we would like to thank the members of our laboratory for their careful reading and critique of our manuscript.

Duality of interest The authors declare that there is no duality of interest associated with this manuscript.

\section{References}

1. Wang Y, Beydoun MA (2007) The obesity epidemic in the United States-gender, age, socioeconomic, racial/ethnic, and geographic characteristics: a systematic review and meta-regression analysis. Epidemiol Rev 29:6-28

2. Reilly MP, Rader DJ (2003) The metabolic syndrome: more than the sum of its parts? Circulation 108:1546-1551

3. Moller DE, Kaufman KD (2005) Metabolic syndrome: a clinical and molecular perspective. Annu Rev Med 56:45-62 
4. Reaven GM (1988) Banting lecture 1988. Role of insulin resistance in human disease. Diabetes 37:1595-1607

5. Adams KF, Schatzkin A, Harris TB et al (2006) Overweight, obesity, and mortality in a large prospective cohort of persons 50 to 71 years old. N Engl J Med 355:763-778

6. Flegal KM, Carroll MD, Ogden CL, Johnson CL (2002) Prevalence and trends in obesity among US adults, 1999-2000. Jama 288:1723-1727

7. Lewis CE, Pollard JW (2006) Distinct role of macrophages in different tumor microenvironments. Cancer Res 66:605-612

8. Xu H, Barnes GT, Yang Q et al (2003) Chronic inflammation in fat plays a crucial role in the development of obesity-related insulin resistance. J Clin Invest 112:1821-1830

9. Di Gregorio GB, Yao-Borengasser A, Rasouli N et al (2005) Expression of CD68 and macrophage chemoattractant protein-1 genes in human adipose and muscle tissues: association with cytokine expression, insulin resistance, and reduction by pioglitazone. Diabetes 54:2305-2313

10. Kanda H, Tateya S, Tamori Y et al (2006) MCP-1 contributes to macrophage infiltration into adipose tissue, insulin resistance, and hepatic steatosis in obesity. J Clin Invest 116:14941505

11. Weisberg SP, Hunter D, Huber R et al (2006) CCR2 modulates inflammatory and metabolic effects of high-fat feeding. J Clin Invest 116:115-124

12. Glass CK, Witztum JL (2001) Atherosclerosis. the road ahead. Cell 104:503-516

13. Libby P (2002) Inflammation in atherosclerosis. Nature 420:868874

14. Weisberg SP, McCann D, Desai M, Rosenbaum M, Leibel RL, Ferrante AW Jr (2003) Obesity is associated with macrophage accumulation in adipose tissue. J Clin Invest 112:1796-1808

15. Munford RS, Hall CL (1986) Detoxification of bacterial lipopolysaccharides (endotoxins) by a human neutrophil enzyme. Science 234:203-205

16. Hwang D (2001) Modulation of the expression of cyclooxygenase- 2 by fatty acids mediated through toll-like receptor 4-derived signaling pathways. Faseb J 15:2556-2564

17. Lee JY, Ye J, Gao Z et al (2003) Reciprocal modulation of Tolllike receptor-4 signaling pathways involving MyD88 and phosphatidylinositol 3-kinase/AKT by saturated and polyunsaturated fatty acids. J Biol Chem 278:37041-37051

18. Shi H, Kokoeva MV, Inouye K, Tzameli I, Yin H, Flier JS (2006) TLR4 links innate immunity and fatty acid-induced insulin resistance. J Clin Invest 116:3015-3025

19. Suganami T, Tanimoto-Koyama K, Nishida J et al (2007) Role of the Toll-like receptor $4 / \mathrm{NF}-\mathrm{kappaB}$ pathway in saturated fatty acid-induced inflammatory changes in the interaction between adipocytes and macrophages. Arterioscler Thromb Vasc Biol 27:84-91

20. Lee JY, Sohn KH, Rhee SH, Hwang D (2001) Saturated fatty acids, but not unsaturated fatty acids, induce the expression of cyclooxygenase-2 mediated through Toll-like receptor 4. J Biol Chem 276:16683-16689

21. Lee JY, Plakidas A, Lee WH et al (2003) Differential modulation of Toll-like receptors by fatty acids: preferential inhibition by $n-3$ polyunsaturated fatty acids. J Lipid Res 44:479-486

22. Weatherill AR, Lee JY, Zhao L, Lemay DG, Youn HS, Hwang DH (2005) Saturated and polyunsaturated fatty acids reciprocally modulate dendritic cell functions mediated through TLR4. J Immunol 174:5390-5397

23. Tsukumo DM, Carvalho-Filho MA, Carvalheira JB et al (2007) Loss-of-function mutation in Toll-like receptor 4 prevents dietinduced obesity and insulin resistance. Diabetes 56:1986-1998

24. Poggi M, Bastelica D, Gual P et al (2007) C3H/HeJ mice carrying a toll-like receptor 4 mutation are protected against the develop- ment of insulin resistance in white adipose tissue in response to a high-fat diet. Diabetologia 50:1267-1276

25. Suganami T, Mieda T, Itoh M, Shimoda Y, Kamei Y, Ogawa Y (2007) Attenuation of obesity-induced adipose tissue inflammation in $\mathrm{C} 3 \mathrm{H} / \mathrm{HeJ}$ mice carrying a Toll-like receptor 4 mutation. Biochem Biophys Res Commun 354:45-49

26. Coenen KR, Gruen ML, Chait A, Hasty AH (2007) Dietinduced increases in adiposity, but not plasma lipids, promote macrophage infiltration into white adipose tissue. Diabetes 56:564-573

27. Coenen KR, Hasty AH (2007) Obesity potentiates development of fatty liver and insulin resistance, but not atherosclerosis in high fat diet-fed agouti LDLR deficient mice. Am J Physiol Endocrinol Metab 293:E492-E499

28. Ayala JE, Bracy DP, McGuinness OP, Wasserman DH (2006) Considerations in the design of hyperinsulinemic-euglycaemic clamps in the conscious mouse. Diabetes 55:390-397

29. Livak KJ, Schmittgen TD (2001) Analysis of relative gene expression data using real-time quantitative PCR and the 2(-Delta Delta C(T)) Method. Methods 25:402-408

30. Saraswathi V, Hasty AH (2006) The role of lipolysis in mediating the proinflammatory effects of very low density lipoproteins in mouse peritoneal macrophages. J Lipid Res 47:1406-1415

31. Davis JE, Gabler NK, Walker-Daniels J, Spurlock ME (2008) Tlr-4 deficiency selectively protects against obesity induced by diets high in saturated fat. Obesity (Silver Spring) 16:12481255

32. Subramanian S, Han CY, Chiba T et al (2008) Dietary cholesterol worsens adipose tissue macrophage accumulation and atherosclerosis in obese LDL receptor-deficient mice. Arterioscler Thromb Vasc Biol 28:685-691

33. Mountjoy KG, Mortrud MT, Low MJ, Simerly RB, Cone RD (1994) Localization of the melanocortin-4 receptor (MC4-R) in neuroendocrine and autonomic control circuits in the brain. Mol Endocrinol 8:1298-1308

34. Lu D, Willard D, Patel IR et al (1994) Agouti protein is an antagonist of the melanocyte-stimulating-hormone receptor. Nature 371:799-802

35. Saraswathi V, Gao L, Morrow JD, Chait A, Niswender KD, Hasty AH (2007) Fish oil increases cholesterol storage in white adipose tissue with concomitant decreases in inflammation, hepatic steatosis, and atherosclerosis in mice. J Nutr 137:1776-1782

36. Michelsen KS, Arditi M (2006) Toll-like receptor signaling and atherosclerosis. Curr Opin Hematol 13:163-168

37. Pasterkamp G, van Keulen JK, de Kleijn DP (2004) Role of Tolllike receptor 4 in the initiation and progression of atherosclerotic disease. Eur J Clin Invest 34:328-334

38. Michelsen KS, Wong MH, Shah PK et al (2004) Lack of Toll-like receptor 4 or myeloid differentiation factor 88 reduces atherosclerosis and alters plaque phenotype in mice deficient in apolipoprotein E. Proc Natl Acad Sci U S A 101:10679-10684

39. Michelsen KS, Doherty TM, Shah PK, Arditi M (2004) TLR signaling: an emerging bridge from innate immunity to atherogenesis. J Immunol 173:5901-5907

40. Arbour NC, Lorenz E, Schutte BC et al (2000) TLR4 mutations are associated with endotoxin hyporesponsiveness in humans. Nat Genet 25:187-191

41. Kiechl S, Lorenz E, Reindl M et al (2002) Toll-like receptor 4 polymorphisms and atherogenesis. N Engl J Med 347:185-192

42. Ameziane N, Beillat T, Verpillat P et al (2003) Association of the Toll-like receptor 4 gene Asp299Gly polymorphism with acute coronary events. Arterioscler Thromb Vasc Biol 23:e61-e64

43. Hartvigsen K, Binder CJ, Hansen LF et al (2007) A diet-induced hypercholesterolemic murine model to study atherogenesis without obesity and metabolic syndrome. Arterioscler Thromb Vasc Biol 27:878-885 